\title{
Estaquia de Cuphea calophylla subsp. mesostemon (Koehne) Lourteig (Lythraceae)
}

\author{
LUSA, M.G. ; BIASI, L.A. ${ }^{2 *}$ \\ 1Departamento de Botânica, Caixa Postal 19031, makelilus@yahoo.com.br 2Departamento de Fitotecnia e \\ Fitossanitarismo, Caixa Postal 19061, Universidade Federal do Paraná, CEP: 81523-990, Curitiba-Brasil \\ *biasi@ufpr.br
}

\begin{abstract}
RESUMO: As informações a respeito da propagação de Cuphea calophylla subsp. mesostemon (Koehne) Lourteig (Lythraceae) são escassas. As técnicas de propagação podem subsidiar o manejo, fornecendo alternativa para produtores de plantas medicinais e evitando a coleta indiscriminada. O presente trabalho teve como objetivo verificar o efeito de diferentes tipos de estaca, tamanhos e área foliar no enraizamento de estacas semilenhosas. As estacas foram obtidas a partir de plantas espontâneas coletadas na Estação Experimental do Canguiri da Universidade Federal do Paraná (UFPR), localizada em Pinhais - PR. Os experimentos com estaquia foram conduzidos em casa-de-vegetação. O delineamento foi inteiramente casualizado com cinco repetições e 24 estacas por parcela, para todos os experimentos. As estacas obtidas de ramos vegetativos apresentaram maior porcentagem de brotação e massa seca de raízes por estaca em relação àquelas obtidas de ramos reprodutivos, especialmente, as estacas obtidas da parte basal dos ramos vegetativos. As estacas preparadas com 10 e $15 \mathrm{~cm}$ de comprimento apresentaram maior número de brotos e maior massa seca de raízes por estaca, em relação às preparadas com $5 \mathrm{~cm}$. As estacas com 3 e 4 pares de folhas apresentaram maior altura, incremento de altura, massa seca de raízes e de brotos por estaca, em relação aos tratamentos com 1 e 2 pares de folhas. Os resultados de propagação vegetativa apontam a estaquia como uma técnica viável para a multiplicação da espécie.
\end{abstract}

Palavras-chave: estaquia, plantas medicinais, enraizamento adventício

ABSTRACT: Cutting of Cuphea calophylla subsp. mesostemon (Koehne) Lourteig (Lythraceae). Information about the propagation of Cuphea calophylla subsp. mesostemon (Koehne) Lourteig (Lythraceae) is scarce. Propagation techniques may support its management, providing an alternative for medicinal plant producers and avoiding indiscriminate harvests. This study aimed to investigate the effect of different types, sizes and leaf areas of semi-woody cuttings on their rooting. Cuttings were obtained from weeds harvested at the Canguiri Experimental Station of the Paraná Federal University (UFPR), Pinhais Municipality, Paraná State, Brazil. Experiments were carried out in a greenhouse. Experimental design was completely randomized, with five replicates and 24 cuttings per plot. Cuttings obtained from vegetative branches had higher sprouting percentage and root dry matter per cutting relative to those obtained from reproductive branches, especially cuttings obtained from the basal region of vegetative branches. Cuttings prepared with 10 and $15 \mathrm{~cm}$ length had larger number of sprouts and higher root dry matter per cutting relative to those prepared with $5 \mathrm{~cm}$. Cuttings presenting 3 and 4 leaf pairs had greater height, increase in height, and root and sprout dry matter per cutting relative to those presenting 1 and 2 leaf pairs. The results regarding vegetative propagation indicate cutting as a viable technique for the multiplication of this species.

Key words: cutting, medicinal plants, adventitious rooting

\section{INTRODUÇÃO}

Algumas espécies do gênero Cuphea são utilizadas para fins medicinais e são popularmente conhecidas como sete-sangrias, sendo utilizadas no controle da hipertensão arterial e na prevenção da arteriosclerose, além de serem atribuídas a elas propriedades diaforética, diurética, laxativa e antiluética. A planta inteira é utilizada sob a forma de chá, xarope e extrato alcoólico por via oral e

Recebido para publicação em 30/06/2009

Aceito para publicação em 26/07/2010

Rev. Bras. PI. Med., Botucatu, v.13, n.1, p.52-57, 2011. 
compressas locais (Lorenzi \& Matos, 2002).

O gênero Cuphea compreende mais de 250 espécies de plantas herbáceas anuais e perenes apresentando grande potencial para as indústrias química, alimentícia e farmacêutica, já que as sementes apresentam ácidos graxos de grande importância (Amarasinghe et al., 1991).

As espécies do gênero Cuphea são consideradas grandes produtoras de óleos compostos de triglicerídeos com ácidos graxos de cadeia média, os quais são de grande interesse ao mercado, principalmente de sabões e detergentes, plásticos e lubrificantes. Além disso, estudos a cerca das sementes de Cuphea tem buscado averiguar a importância nutricional dessas espécies (Carlson et al., 1993).

As espécies do gênero Cuphea, utilizadas na medicina popular, são conhecidas por prevenirem doenças cardiovasculares e por serem eficazes contra hipertensão e arteriosclerose. Schuldt et al. (2004) confirmaram a ação antioxidante dos compostos fenólicos e flavonóides encontrados nos extratos hidroalcoólico e butanólico e na fração acetato de etila, das folhas de $C$. cartaginensis (Jacq.) e sugerem que tal atividade tem importantes efeitos sobre a saúde, concordando com a terapêutica popular. Duarte et al. (2002) descreveram para as partes aéreas floridas de C. carthaginensis (Jacq.) a presença de taninos condensados, proantocianidinas, esteróides e flavonóides. Conforme os autores, tais princípios ativos devem estar relacionados aos efeitos antibióticos, observados sobre bactérias gram-positivas e gramnegativas. Além desses autores, Perez-Castorena \& Maldonado (2003) descrevem a presença de triterpenos e glicosídeos flavonóides para $C$. wrightii (A. Gray).

Cuphea calophylla subsp. mesostemon (Koehne) Lourteig é uma planta herbácea ruderal de crescimento espontâneo e de ocorrência em campos, gramados, bordos de mata, beiras de estradas e pastagens em todo o Brasil. Mede cerca de 10 a 30 $\mathrm{cm}$ e é totalmente recoberta por tricomas, possuindo caule avermelhado. As folhas apresentam forma variável, de ovadas a lanceoladas e filotaxia oposta. A planta floresce de setembro a abril e as flores são isoladas ou reunidas em inflorescências do tipo cimeira ramificada e providas de hipsofilos (Shoenberg \& Oliveira,1989). A respeito da propagação do gênero Cuphea, a prática usual de cultivo nos Estados Unidos, tem sido a semeadura (Gesh et al., 2003; Gesh et al., 2006). Nessa modalidade de propagação, Gesh et al. (2003) demonstraram que o maior rendimento da cultura foi obtido quando as plantas foram cultivadas em linhas mais espaçadas, com 75 $\mathrm{cm}$ de distância entre as mesmas, devido à competição entre as plantas por luz e nutrientes.

De acordo com Gesh et al. (2006), o cultivo de Cuphea, especialmente do híbrido PSR23, obtido a partir da hibridização interespecífica de Cuphea viscosissima Jacq. (nativa dos Estados Unidos) com C. lanceolata W.T. Aiton (nativa do México), tem sido realizado nos Estados Unidos com sucesso.

No Brasil, o cultivo por semeadura de Cuphea ainda é desconhecido, não havendo mercado para absorver a produção em larga escala, destinada à indústria cosmética, química e alimentícia. No entanto, como muitas espécies do gênero são consideradas medicinais, é necessário conhecer as técnicas de propagação para a produção, já que essa pode constituir uma alternativa técnica e economicamente viável, principalmente, para propriedades de pequeno porte.

A reprodução vegetativa ou clonal é o método de propagação mais utilizado na produção comercial de diversas culturas ornamentais e frutíferas, tendo como vantagens a reprodução de todas as características da planta matriz, a uniformidade nas populações, a facilidade de propagação (Hartmann et al., 2002) e o rápido aumento no número de plantas, já que se pode produzir grande quantidade de mudas a partir de apenas uma planta matriz (Hill, 1996).

A estaquia é a técnica de propagação vegetativa mais rápida e mais fácil para execução, sendo muito utilizada nas espécies que apresentam maior facilidade para a formação de raízes adventícias. Dentre os diversos tipos de estaca, as semilenhosas apresentam bons resultados de enraizamento devido à presença de folhas, que produzem substâncias de reserva e hormonais, necessárias para a indução e desenvolvimento radicial (Hartmann et al., 2002).

Inúmeras espécies de interesse comercial podem ser multiplicadas por estaquia, sendo que 0 enraizamento dessas estacas é influenciado positiva ou negativamente por fatores intrínsecos, como condição fisiológica e idade da planta-matriz, presença de folhas e gemas, tipo de estaca, época do ano, estiolamento, juvenilidade e balanço hormonal, e extrínsecos, como a temperatura, luz, umidade, substrato e condicionamento (Hartmann et al., 2002; Fachinello et al., 2005).

As plantas medicinais nativas, utilizadas pela população, se desenvolvem naturalmente nas diferentes formações vegetacionais do país. A coleta indiscriminada, sem qualquer critério técnico, pode representar risco para o consumidor do fitoterápico, já que pode ocorrer a troca de espécies ou a mistura com outros materiais indesejáveis, além da depredação do patrimônio genético vegetal e do risco de extinção, pela exploração predatória. Torna-se clara, a crescente necessidade do estudo sobre as plantas medicinais, em especial sobre aquelas nativas, pela importância de uso pela população local e importância científica. Assim, o estudo do manejo, visa preservar as espécies nativas e explorar os inúmeros recursos da flora local ainda pouco conhecidos (Corrêa Júnior et al., 2004). 
As informações a respeito da propagação de Cuphea calophylla subsp. mesostemon (Koehne) Lourteig são escassas. Recentemente foi avaliada a fenologia desta espécie em Curitiba-PR, sendo observado que a planta apresenta floração, frutificação e dispersão das sementes durante todo o ano (Martini et al., 2010). É provável que essas sementes sejam viáveis, mas são pequenas e o fruto maduro se abre rapidamente liberando-as no ambiente, o que dificulta a sua coleta para a produção de mudas.

Portanto, o presente trabalho teve como objetivo verificar o efeito de diferentes tipos de estaca, tamanhos e área foliar no enraizamento de estacas semilenhosas de Cuphea calophylla subsp. mesostemon (Koehne) Lourteig (Lythraceae), como subsídio para o manejo.

\section{MATERIAL E MÉTODO}

O material botânico de Cuphea calophylla subsp. mesostemon (Koehne) Lourteig (Lythraceae) foi coletado durante os meses de agosto de 2006 a abril de 2007, na Estação Experimental do Canguiri, Universidade Federal do Paraná (UFPR), latitude 2525'S, longitude 40ㄴ' $\mathrm{W}$ e altitude média de 930 $\mathrm{m}$, localizada no município de Pinhais - PR.

Coletou-se plantas férteis para a montagem de exsicatas, as quais foram posteriormente depositadas no herbário UPCB, do Departamento de Botânica, UFPR, em Curitiba, onde se encontram tombadas sob o registro № 51.907 .

As coletas dos ramos foram realizadas no período da manhã, entre 8:00 e 10:00 horas, no mesmo dia de preparo das estacas. Os ramos foram umedecidos e acondicionados em sacos plásticos e transportados para o Setor de Ciências Agrárias, onde foram colocados em baldes de água, para a redução da desidratação até o término do preparo das estacas. Os experimentos foram conduzidos em casa-devegetação localizada no Departamento de Fitotecnia e Fitossanitarismo, Setor de Ciências Agrárias, Universidade Federal do Paraná, Curitiba - PR.

Os experimentos realizados envolveram o estudo de tamanhos de estaca, tipos de estaca e efeito do número de folhas no enraizamento das estacas. O experimento para testar os tamanhos de estaca foi composto pelos tratamentos de 5, 10 e 15 $\mathrm{cm}$ de comprimento. As estacas possuíam um par de folhas na parte superior. $O$ delineamento foi inteiramente casualizado com cinco repetições e 24 estacas por parcela. Após 43 dias foi realizada a avaliação dos parâmetros, como porcentagem de estacas enraizadas, porcentagem de estacas brotadas, porcentagem de estacas mortas, número de brotos por estaca, altura média, incremento de altura e massa seca média de raízes por estaca.

Os tipos de estaca testados envolveram estacas apicais e basais de plantas em fase vegetativa e reprodutiva (florescimento). As estacas possuíam 10 $\mathrm{cm}$ e um par de folhas na parte superior. O delineamento foi inteiramente casualizado com cinco repetições e 24 estacas por parcela. Após 42 dias foi realizada a avaliação para os mesmos parâmetros descritos anteriormente, exceto pelo número de brotos por estaca e pela altura média.

No experimento com diferente número de folhas por estaca foram testadas estacas sem folhas, com um par de folhas e com dois, três e quatro pares de folhas. As estacas foram padronizadas com 10 $\mathrm{cm}$ de comprimento. $O$ delineamento foi inteiramente casualizado com cinco repetições e 24 estacas por parcela. Após 45 dias foi realizada a avaliação para os mesmos parâmetros descritos anteriormente, além de considerar a altura média, e a massa seca média de brotos por estaca.

O plantio foi realizado em tubetes de polipropileno com capacidade de $53 \mathrm{~cm}^{3}$, utilizandose vermiculita de granulometria média como substrato para todos os experimentos. As estacas foram mantidas em casa-de-vegetação climatizada com temperatura de $25 \pm 5^{\circ} \mathrm{C}$ e com irrigação intermitente de 15 segundos a cada 30 minutos durante o dia e a cada hora durante a noite.

Para a realização da análise estatística os dados foram submetidos à análise de variância e, para a comparação de médias, ao Teste de Duncan a 5\% de probabilidade.

\section{RESULTADO}

No experimento com diferentes tamanhos de estaca (Tabela 1) foi observado que todos os tratamentos tiveram altas taxas de enraizamento e de brotação, e baixas porcentagens de mortalidade, não diferindo significativamente entre si. As raízes tiveram origem ao longo da porção do caule que permaneceu dentro do substrato e as brotações foram provenientes das gemas axilares existentes na estaca. As estacas de 10 e $15 \mathrm{~cm}$, apresentaram maior número de brotos e maior massa seca de raízes por estaca, em relação às estacas de $5 \mathrm{~cm}$. As estacas preparadas com $15 \mathrm{~cm}$ de comprimento apresentaram maior altura, sendo estatisticamente superiores àquelas com 5 e $10 \mathrm{~cm}$. Observando o incremento de altura, as estacas com $10 \mathrm{~cm}$ foram superiores aos demais tamanhos de estacas, diferindo significativamente das estacas com $15 \mathrm{~cm}$.

Em relação aos tipos de estaca (Tabela 2), todos os tratamentos apresentaram alta taxa de enraizamento e baixa mortalidade, não diferindo entre si. No entanto, observou-se uma tendência de maior mortalidade nas estacas obtidas de ramos apicais reprodutivos. As estacas preparadas com a porção basal na fase vegetativa apresentaram maior porcentagem de brotação do que as estacas na fase reprodutiva. As 
estacas apicais e basais na fase vegetativa também apresentaram maior massa seca de raízes por estaca, diferindo significativamente das estacas preparadas a partir de ramos na fase reprodutiva.

Nos experimentos em que se avaliou o efeito da área foliar sobre o desenvolvimento da estaca (Tabela 3), o tratamento com estacas sem folhas demonstrou desenvolvimento estatisticamente inferior aos demais, com relação a porcentagem de estacas enraizadas e brotadas, altura e incremento da altura das mudas e massa seca das raízes e de brotos emitidos por estaca. A mortalidade foi muito elevada e estatisticamente superior no tratamento com estacas sem folhas. As estacas contendo folhas não diferiram entre si para a porcentagem de enraizamento, brotação e mortalidade. As estacas com três e quatro pares de folhas apresentaram maior altura, incremento de altura, massa seca de raízes e de brotos por estaca, em relação aos tratamentos com um e dois pares de folhas.

TABELA 1. Porcentagem de estacas enraizadas, brotadas e mortas, número de brotos por estaca, altura e incremento da altura das mudas e massa seca das raízes emitidas por estaca de Cuphea calophylla subsp. mesostemon (Koehne) Lourteig (Lythraceae) preparadas com diferentes tamanhos. Curitiba-PR. 2007.

\begin{tabular}{|c|c|c|c|c|c|c|c|}
\hline $\begin{array}{l}\text { Tamanho } \\
(\mathrm{cm})\end{array}$ & $\begin{array}{c}\text { Enraizamento } \\
(\%)\end{array}$ & $\begin{array}{c}\text { Brotação } \\
(\%)\end{array}$ & $\begin{array}{l}\text { Mortalid ade } \\
(\%)^{2}\end{array}$ & $\begin{array}{l}\text { № de brotos } \\
\text { por estaca }\end{array}$ & $\begin{array}{l}\text { Altura } \\
(\mathrm{cm})\end{array}$ & 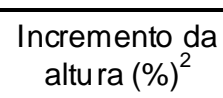 & $\begin{array}{c}\text { Massa seca de raízes } \\
\text { por estaca }(\mathrm{mg})\end{array}$ \\
\hline 15 & $86,7 a^{1}$ & $84,9 a$ & $13,3 \mathrm{a}$ & $2,3 a$ & $18,4 \mathrm{a}$ & $22,8 b$ & $57 a$ \\
\hline 10 & $90,0 \mathrm{a}$ & $89,2 \mathrm{a}$ & $9,2 \mathrm{a}$ & $2,1 \mathrm{a}$ & $15,2 b$ & $35,1 \mathrm{a}$ & $47 a$ \\
\hline 5 & $85,0 \mathrm{a}$ & $76,7 \mathrm{a}$ & $9,2 \mathrm{a}$ & $1,3 b$ & $9,5 \mathrm{c}$ & $30,5 \mathrm{ab}$ & $25 \mathrm{~b}$ \\
\hline C.V.(\%) & 10,6 & 12,3 & 40,2 & 17,7 & 8,9 & 14,5 & 20,8 \\
\hline
\end{tabular}

${ }^{1}$ Médias seguidas pela mesma letra não diferem significativamente pelo teste de Duncan a $5 \%$ de probabilidade de erro. ${ }^{2}$ Dados originais transformados para análise em raiz $(x+1)$.

TABELA 2. Porcentagem de estacas enraizadas, brotadas e mortas e massa seca das raízes emitidas por estaca de Cuphea calophylla subsp. mesostemon (Koehne) Lourteig (Lythraceae) preparadas da região apical e basal de ramos em fase vegetativa e reprodutiva. Curitiba-PR. 2007.

\begin{tabular}{lcccc}
\hline Tratamentos & $\begin{array}{c}\text { Enraizamento } \\
(\%)\end{array}$ & $\begin{array}{c}\text { Mortalidade } \\
(\%)^{2}\end{array}$ & $\begin{array}{c}\text { Brotação } \\
(\%)\end{array}$ & $\begin{array}{c}\text { Massa seca de raízes por } \\
\text { estaca }(\mathrm{mg})\end{array}$ \\
\hline Apical vegetativa & $95,8 \mathrm{a}^{1}$ & $4,2 \mathrm{a}$ & $63,3 \mathrm{ab}$ & $33,0 \mathrm{a}$ \\
Basal ve getativa & $98,3 \mathrm{a}$ & $2,5 \mathrm{a}$ & $80,8 \mathrm{a}$ & $30,0 \mathrm{a}$ \\
Apical reprodutiva & $88,3 \mathrm{a}$ & $11,6 \mathrm{a}$ & $48,3 \mathrm{~b}$ & $16,0 \mathrm{~b}$ \\
Basal reprodutiva & $95,0 \mathrm{a}$ & $5,0 \mathrm{a}$ & $53,3 \mathrm{~b}$ & $21,4 \mathrm{~b}$ \\
\hline C.V.(\%) & 8,6 & 53,7 & 24,9 & 22,1 \\
\hline
\end{tabular}

${ }^{1}$ Médias seguidas pela mesma letra não diferem significativamente pelo teste de Duncan a $5 \%$ de probabilidade de erro. ${ }^{2}$ Dados originais transformados para análise em raiz $(x+1)$.

TABELA 3. Porcentagem de estacas enraizadas, brotadas e mortas, altura e incremento da altura das mudas e massa seca das raízes e de brotos emitidos por estaca de Cuphea calophylla subsp. mesostemon (Koehne) Lourteig (Lythraceae) preparadas com diferentes números de folhas. Curitiba-PR. 2007.

\begin{tabular}{lccccccc}
\hline $\begin{array}{c}\text { Número de } \\
\text { folhas }\end{array}$ & $\begin{array}{c}\text { Enraizamento } \\
(\%)\end{array}$ & $\begin{array}{c}\text { Brotação } \\
(\%)\end{array}$ & $\begin{array}{c}\text { Mortalidade } \\
(\%)^{2}\end{array}$ & $\begin{array}{c}\text { Altura } \\
(\mathrm{cm})\end{array}$ & $\begin{array}{c}\text { Incremento } \\
\text { da altura } \\
(\%)^{2}\end{array}$ & $\begin{array}{c}\text { Massa seca de } \\
\text { raízes por estaca } \\
(\mathrm{mg})\end{array}$ & $\begin{array}{c}\text { Mass a seca de } \\
\text { brotos por estaca } \\
(\mathrm{mg})\end{array}$ \\
\hline Sem folha & $39,6 \mathrm{~b}^{1}$ & $38,5 \mathrm{~b}$ & $60,4 \mathrm{a}$ & $10,2 \mathrm{c}$ & $2,7 \mathrm{c}$ & $8 \mathrm{c}$ & $28 \mathrm{c}$ \\
1 par & $87,5 \mathrm{a}$ & $85,4 \mathrm{a}$ & $8,3 \mathrm{~b}$ & $12,5 \mathrm{~b}$ & $25,6 \mathrm{~b}$ & $33 \mathrm{~b}$ & $76 \mathrm{~b}$ \\
2 pares & $91,7 \mathrm{a}$ & $77,1 \mathrm{a}$ & $7,3 \mathrm{~b}$ & $12,2 \mathrm{~b}$ & $22,3 \mathrm{~b}$ & $44 \mathrm{~b}$ & $86 \mathrm{~b}$ \\
3 pares & $91,7 \mathrm{a}$ & $88,5 \mathrm{a}$ & $8,3 \mathrm{~b}$ & $14,5 \mathrm{a}$ & $45,1 \mathrm{a}$ & $67 \mathrm{a}$ & $125 \mathrm{a}$ \\
4 pares & $97,9 \mathrm{a}$ & $93,7 \mathrm{a}$ & $2,1 \mathrm{~b}$ & $13,4 \mathrm{ab}$ & $34,7 \mathrm{ab}$ & $75 \mathrm{a}$ & $106 \mathrm{ab}$ \\
\hline C.V.(\%) & 12,9 & 14,4 & 44,7 & 7,6 & 17,4 & 23,6 & 25,7 \\
\hline
\end{tabular}

${ }^{1}$ Médias seguidas pela mesma letra não diferem significativamente pelo teste de Duncan a $5 \%$ de probabilidade de erro. ${ }^{2}$ Dados originais transformados para análise em raiz $(x+1)$.

Rev. Bras. PI. Med., Botucatu, v.13, n.1, p.52-57, 2011. 


\section{DISCUSSÃO}

Para Hartmann et al. (2002), o tamanho das estacas deve ser estabelecido de acordo com o tipo de lenho, sendo que para as estacas de ramos lenhosos arbóreos, o comprimento pode variar de $10 \mathrm{a}$ $76 \mathrm{~cm}$, dependendo da espécie, já para as estacas de ramos lenhosos arbustivos e de caules semilenhosos, o comprimento pode variar de 7,5 a $12,5 \mathrm{~cm}$. Nos experimentos com sete-sangrias foram observados melhores resultados para o número de brotos e massa seca de raízes com estacas semilenhosas de 10 e 15 $\mathrm{cm}$, quando comparadas às de $5 \mathrm{~cm}$, concordando com os autores supra citados. Estacas semilenhosas maiores também foram preferidas para a estaquia de Lippia alba (Biasi \& Costa, 2003), Baccharis stenocephala (Bona et al., 2004) e Ocimum selloi (Costa et al., 2007). Na estaquia de duas cultivares de oliveira, a porcentagem de enraizamento e o número de raízes por estaca foi superior nas estacas maiores (Oliveira et al., 2003). Provavelmente, as estacas de maior tamanho possuem maior quantidade de reservas, que são translocadas para a formação das raízes adventícias (Hartmann et al., 2002).

A sete-sangrias apresentou taxa de enraizamento semelhante entre as regiões apicais e basais dos ramos e entre ramos em fase vegetativa $e$ em fase reprodutiva. A região de coleta da estaca no ramo, apresenta resposta variável dependendo da espécie em estudo, pois para Pfaffia glomerata a posição basal das estacas apresentou maior enraizamento do que a apical (Nicoloso et al., 1999), já para caramboleira o enraizamento foi superior nas estacas apicais (Bastos et al., 2004). Apesar da porcentagem de estacas enraizadas ter sido semelhante, a formação e crescimento das raízes foi maior nas estacas provenientes de ramos em fase vegetativa. Isso já era esperado, pois durante a fase reprodutiva, a formação das flores e frutos é um dreno dos fotoassimilados (Taiz \& Zeiger, 2004) que concorre com a formação de raízes adventícias. Em plantas de fácil enraizamento, como a carqueja (Baccharis trimera), já foi demonstrado que é possível realizar a estaquia durante a fase reprodutiva, mas com resultados de enraizamento inferiores aos obtidos durante a fase vegetativa (Sousa et al., 2006). O enraizamento de estacas durante a fase de florescimento também foi possível com azaléia (Carvalho et al., 2002).

No experimento em que se avaliou o efeito do número de folhas sobre o desenvolvimento das estacas, verificou-se que a presença e o número de folhas influenciaram no enraizamento e brotação das estacas. De acordo com Assis \& Teixeira (1998), as folhas podem auxiliar na formação de raízes adventícias com a translocação de substâncias, tais como auxinas, sacarose, compostos nitrogenados e vitaminas (só folhas fornecem vitaminas) para a base das estacas, possibilitando assim, o desenvolvimento das raízes. O maior enraizamento com o aumento do número de folhas também foi observado para Aristolochia triangulares (Corrêa \& Biasi, 2003), Lippia alba (Biasi \& Costa, 2003), Mikania laevigata e Mikania glomerata (Lima et al., 2003) e Malpighia glabra (Gontijo et al., 2003).

Entretanto, as folhas podem, em alguns casos, prejudicar o enraizamento devido à perda de água por transpiração (Fachinello et al., 2005). Como o experimento foi instalado sob condição de irrigação intermitente, provavelmente não ocorreu perda de estacas por estresse hídrico ou foi muito pequena, já que a mortalidade foi baixa nas estacas com folhas. Como a porcentagem de enraizamento foi alta em todos os tratamentos com diferentes números de folhas, mesmo sem a utilização de reguladores vegetais, a sete-sangrias pode ser considerada uma espécie de fácil enraizamento.

Para a propagação vegetativa de sete-sangrias por estaquia recomenda-se a utilização de estacas com 10 a $15 \mathrm{~cm}$ de comprimento e 3 ou 4 pares de folhas, provenientes de ramos em fase vegetativa.

\section{REFERÊNCIA}

AMARASINGHE, V.; GRAHAM, S.; GRAHAM, A. Trichome morphology in the genus Cuphea (Lythraceae). Botanical Gazette, v.152, n.1, p.77-90, 1991.

ASSIS, T.A.; TEIXEIRA, S.L. Enraizamento de plantas lenhosas. In: TORRES, A.C.; CALDAS, L.S.; BUSO, J.A. Cultura de tecidos e transformação genética de plantas. Brasília: EMBRAPA, v.1, p.261-97, 1998.

BASTOS, D.C. et al. Influência do ácido indolbutírico no enraizamento de estacas apicais e basais de caramboleira (Averrhoa carambola L.) sob condições de nebulização intermitente. Revista Brasileira de Fruticultura, v.26, n.2, p. 284-6, 2004.

BIASI, L.A.; COSTA, G. Propagação vegetativa de Lippia alba. Ciência Rural, v.33, n.3, p.455-9, 2003.

BONA, C.M. et al. Propagação de três espécies de carqueja com estacas de diferentes tamanhos. Semina: Ciências Agrárias, v.25, n.3, p.179-84, 2004.

CARLSON, K.D.; KLEIMAN, R.; PAVLIK, R.P. Prepress solvent extraction of Cuphea seed. American Oil Chemists' Society, v.70, n.12, p.1269-72, 1993.

CARVALHO, D.B.; SILVA, L.M.; ZUFFELLATO-RIBAS, K.C. Indução de raízes em estacas semilenhosas de azaléia através da aplicação de ácido naftaleno-acético em solução. Scientia Agraria, v.3, n.1-2, p.101-7, 2002.

CORRÊA, C.F.; BIASI, L.A. Área foliar e tipo de substrato na propagação por estaquia de cipó-mil-homens (Aristolochia triangularis Cham. Et Schl.). Revista Brasileira de Agrociência, v.9, n.3, p.233-5, 2003.

CORRÊA JÚNIOR, C.; GRAÇA, L.R.; SCHEFFER, M.C. Complexo agroindustrial das plantas medicinais, aromáticas e condimentares no Estado do Paraná. Curitiba: Sociedade Paranaense de Plantas Medicinais: EMATER-PR: Embrapa florestas, 2004. 272p.

Rev. Bras. Pl. Med., Botucatu, v.13, n.1, p.52-57, 2011. 
COSTA, L.C.B.; PINTO, J.E.B.P.; BERTOLUCCI, S.K.V. Comprimento da estaca e tipo de substrato na propagação vegetativa de atroveran. Ciência Rural, v.37, n.4, p.1157-60, 2007.

DUARTE, M.G.R. et al. Perfil fitoquímico e atividade antibacteriana in vitro de plantas invasoras. Revista Lecta, v.20, n.2, p.177-82, 2002.

FACHINELLO, J.C.; HOFFMANN, A.; NACHTIGAL, J.C. Propagação de plantas frutíferas. Brasília: Embrapa Informação Tecnológica, 2005. 221p.

GESH, R.W. et al. Agricultural management of Cuphea and potential for commercial production in the Northern Corn Belt. Industrial Crops and Products, v.24, p.300-6, 2006.

GESH, R.W. et al. Growth and yield response of Cuphea to row spacing. Field Crop Research, v.81, p.193-9, 2003. GONTIJO, T.C.A. et al. Enraizamento de diferentes tipos de estacas de aceroleira utilizando ácido indolbutírico. Revista Brasileira de Fruticultura, v.25, n.2, p.290-2, 2003.

HARTMANN, H.T. et al. Plant propagation: principles and practices. 6.ed. New Jersey: Prentice Hall, 2002. 880p. HILL, L. Segredos da propagação de plantas. São Paulo: Nobel, 1996. 245p.

LIMA, N.P. et al. Estaquia semilenhosa e análise de metabólitos secundários de guaco (Mikania glomerata Sprengel e Mikania laevigata Schultz Bip. Ex Baker). Revista Brasileira de Plantas Medicinais, v.5, n.2, p.4754, 2003.

LORENZI, H.; MATOS, F.J.A. Plantas medicinais no

Brasil: nativas e exóticas cultivadas. Nova Odessa:
Instituto Plantarum, 2002. 512p.

MARTINI, A. et al. Fenologia de espécies nativas com potencial paisagístico. Semina: Ciências Agrárias, v.31, n.1, p.75-84, 2010.

NICOLOSO, F.T.; FORTUNATO, R.P.; FOGACA, M.A.F. Influência da posição da estaca no ramo sobre o enraizamento de Pfaffia glomerata (Spreng.) Pedersen em dois substratos. Ciência Rural, v.29, n.2, p.277-83, 1999.

OLIVEIRA, A.F. et al. Influência do número de nós em estacas semilenhosas de oliveira (Olea europaea L.) no enraizamento sob câmara de nebulização. Ciência e Agrotecnologia, v.27, n.2, p.332-8, 2003.

PEREZ-CASTORENA, A.L.; MALDONADO, E. Triterpenes and flavonoid glycosides from Cuphea wrightii. Biochemical Systematics and Ecology, v.31, p.331-4, 2003.

SCHULDT, E.Z. et al. Comparative study of radical scavenger activities of crude extract and fractions from Cuphea carthagenensis leaves. Phytomedicine, v.11, p.523-9, 2004.

SHOENBERG, M.M.; OLIVEIRA, S.M.C. Morfo e histogênese de flor, fruto e semente em Cuphea calophylla spp. mesostemon (Koehne) Lourt. Estudos de Biologia, n.19, p.3-47, 1989.

SOUSA, L.A.; SACRAMENTO, L.V.S.; MING, L.C. Propagação por estaquia de três acessos de Baccharis trimera em fenofase reprodutiva. Revista Brasileira de Plantas Medicinais, v.8, n.4, p.189-92, 2006.

TAIZ, L.; ZEIGER, E. Fisiologia vegetal. 3.ed. Porto Alegre: Artmed, 2004. 719p. 